
PAQUA DEEP COLORS

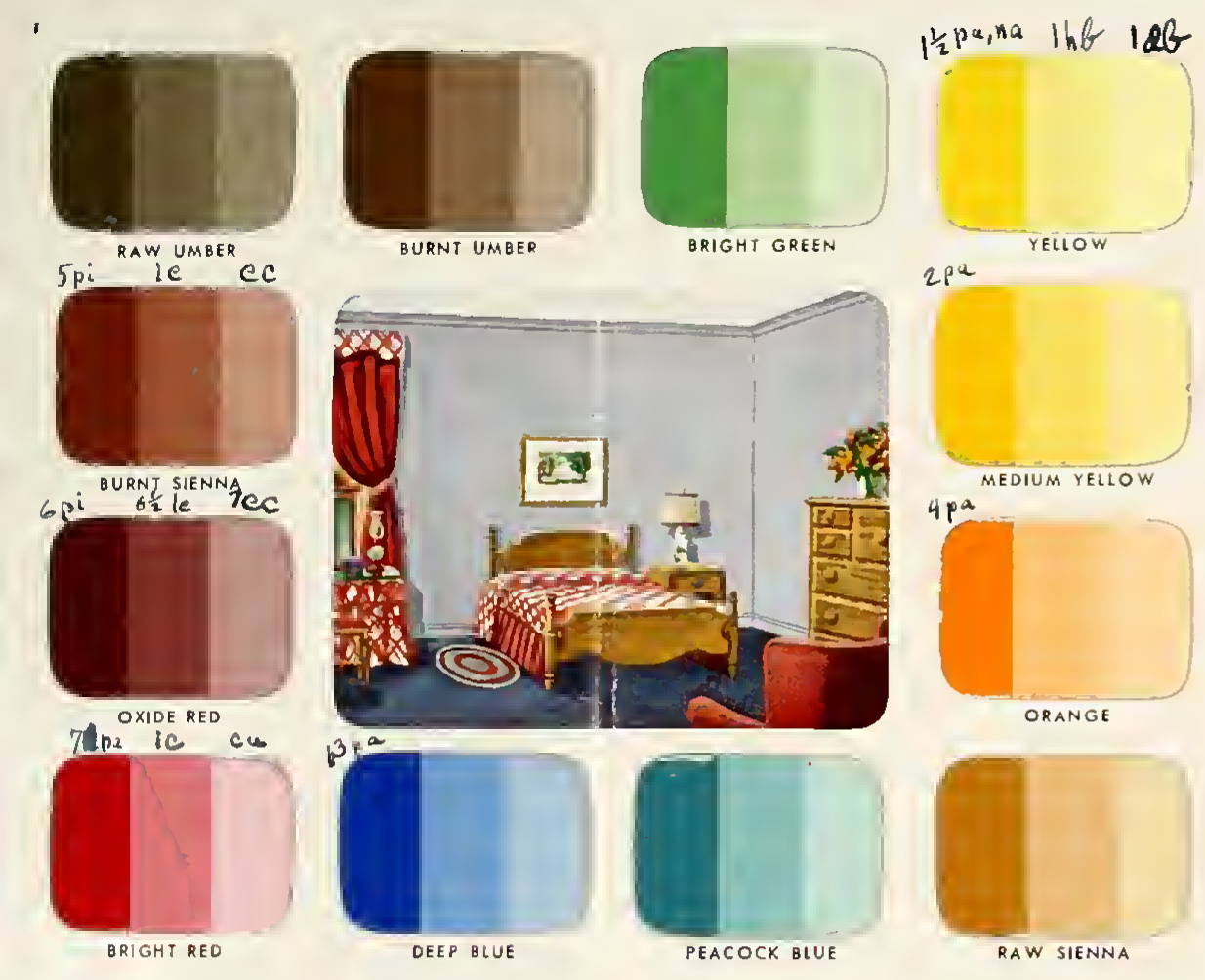

PAQUA DEEP COLORS speak for themselves. They speak in deep, rich tones and they speak soffly too. Strong and uniform, they assure a wide choice in
dark shades for Controctors, Decorators cnd Home Owners. Each sample obove show (left) Stondard Deep Shade - (center) one part Deep Color and two parts White -

PAQUA INTERMIXED SHADES shown on the palette-shoped chips on the extreme right, are through the intermixing of Standard Tints, figuring requirements the intermixtures shown ore mode only from combinotions of gallon, quart and half pint cans.

\section{PAQUA TINTS}

These color chips, made with Paqua,
show the attractive colors and finish show the attractive colors and finish
which this modern decorative material will bring to your' home. The colors are chosen with the purpose in mind of making it possible to decorate adjacent rooms or walls with different ins and maintain a correct balance Many variations of the colors shown can be obtained by intermixing these
tints, or by the addition of White Paqua.

SUNSHINE YELLOW

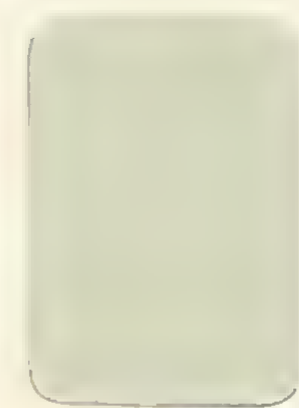

IGHT GRAY
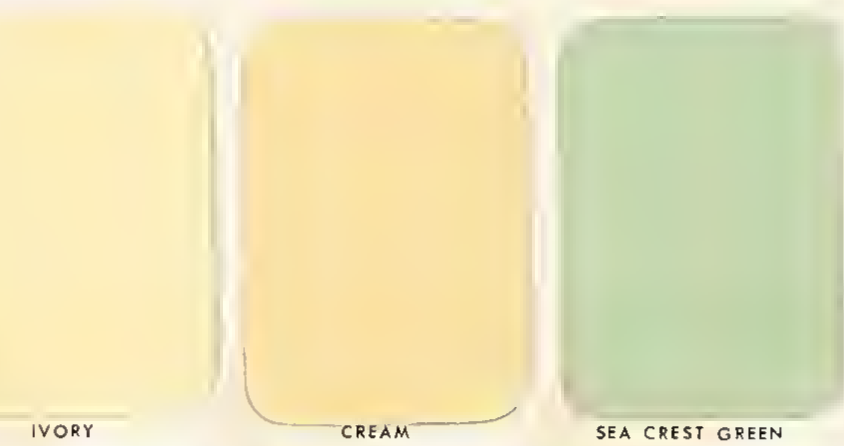

CREAM
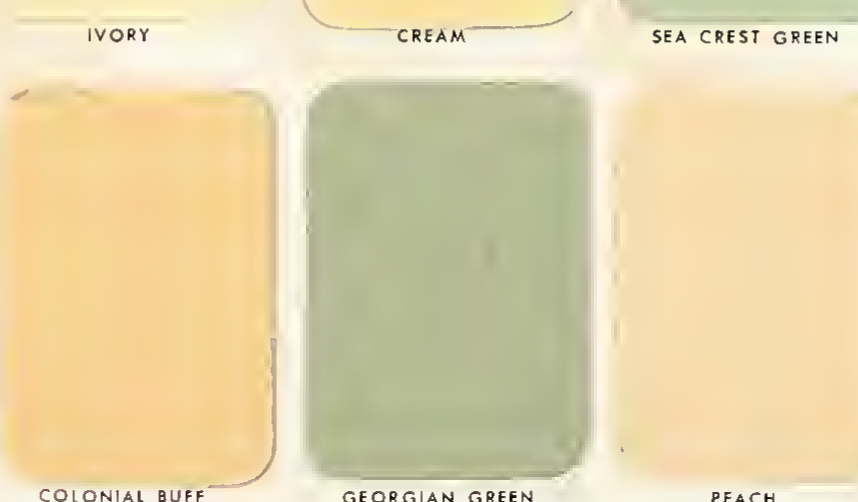

GEORGIAN GREEN
PAQUA INTERMIXED SHADES

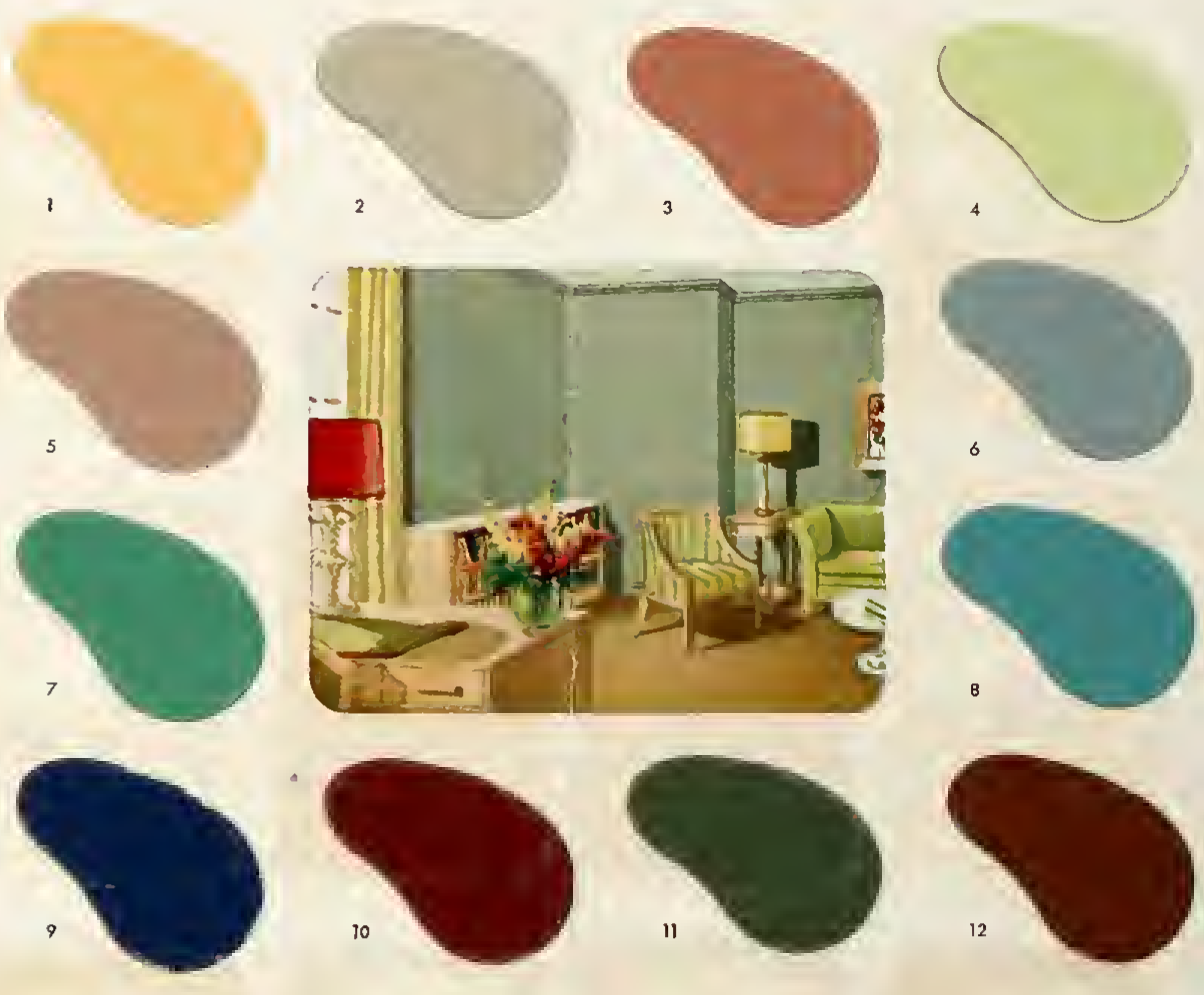

DIRECTIONS FOR MIIING ABOVE SHADES

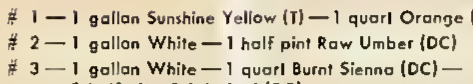

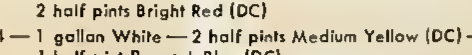

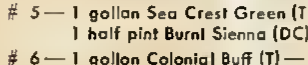

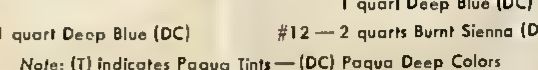




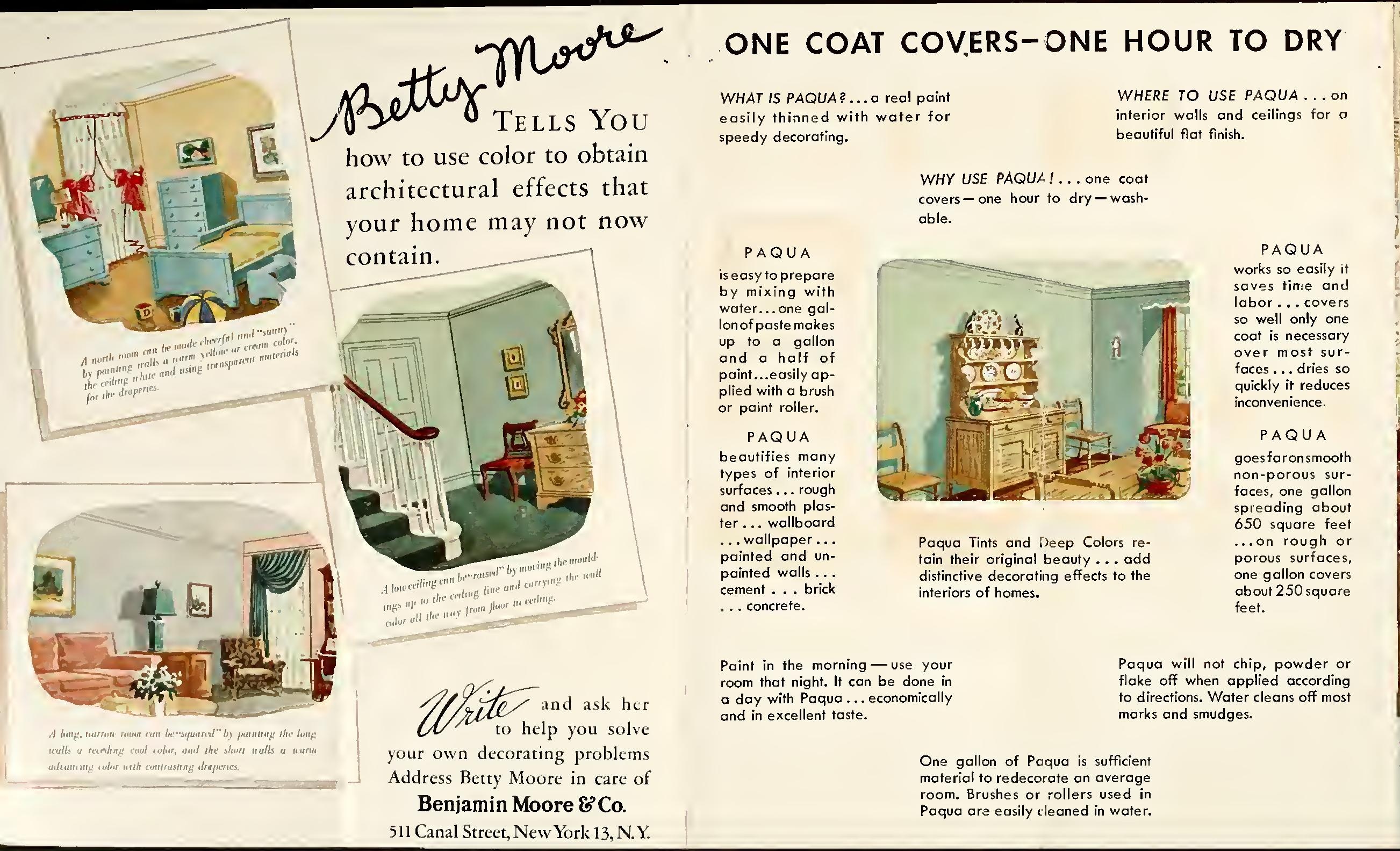

me

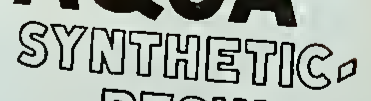

RESRN

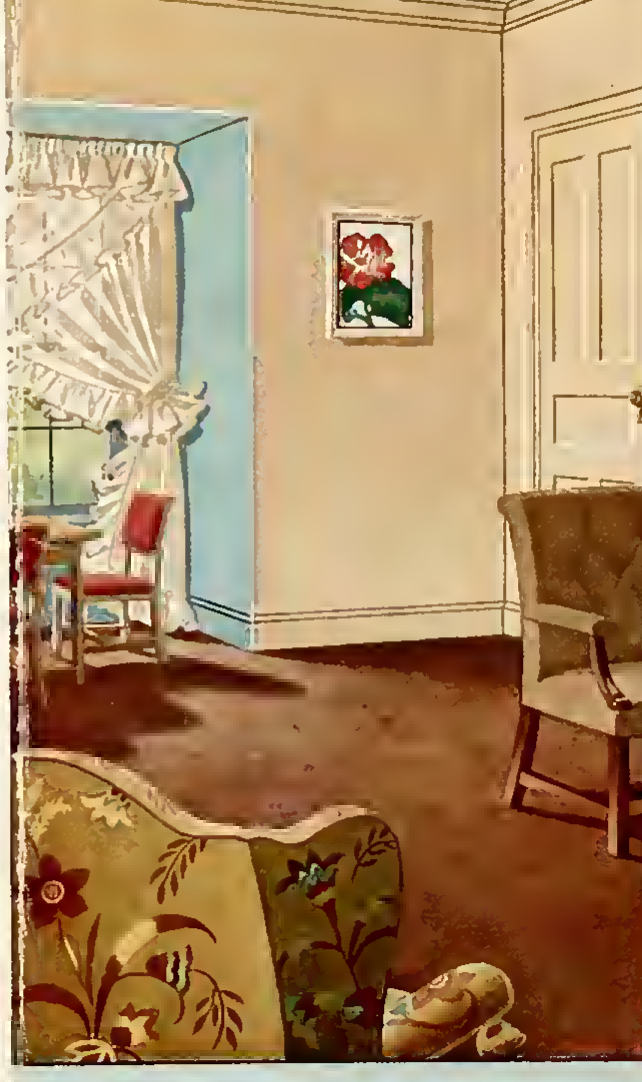

PaINT

on of paste mak

and smooth plas-
ter ... wallboard

Paqua Tints and beep Colors re-

distinctive decorating effects to the

interiors of homes.

Paqua will not chip, powder or to directions. Water cleans off most Benjamin Moore $\mathbb{E}^{\mathrm{CO}}$ 11 Canal Street, New York 13, N.Y. 



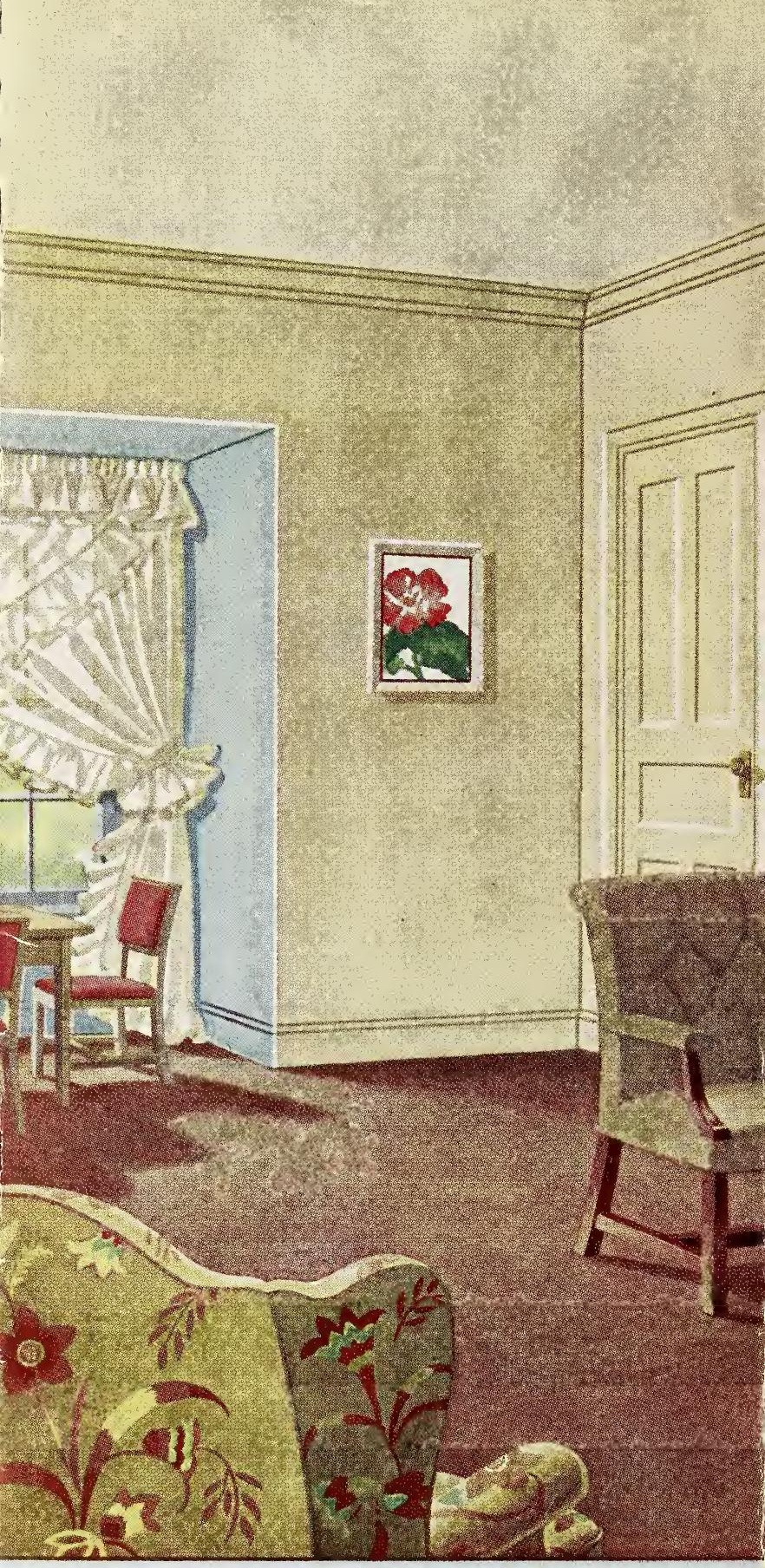

